\title{
DISSOLVED OXYGEN IN GASOLINE AND TANK CORROSION
}

\author{
Preya Ramdeen ${ }^{1}$, Dhurjati Prasad Chakrabarti ${ }^{2 *}$ \\ ${ }^{1,2}$ Department of Chemical Engineering, The University of The West Indies, St Augustine, \\ Trinidad and Tobago. \\ ${ }^{1}$ Email: preyaramdeen@gmail.com \\ ${ }^{2}$ Email dhurjati.chakrabarti@sta.uwi.edu*(Corresponding author)
}

\begin{abstract}
The quantity of gaseous oxygen dissolved in water is generally known as Dissolved Oxygen. However, the oxygen may dissolve in other liquids too. To determine the concentration of Dissolved Oxygen in Gasoline a probe was used to estimate oxygen concentration at different experimental conditions. Comparing the experiments performed on Gasoline and Deionized Water it was found that for gasoline, the equilibrium point was reached earlier, while for the Deionized Water it took a long time for the initial reading to be attained after purging. In determining the mass transfer coefficients of Gasoline and Deionized Water it was found that Gasoline displayed a higher mass transfer coefficient value than Deionized Water. It is concluded that the increase in stirring speed, increases, the mass transfer coefficient and it is more prominent for gasoline. The aim of this work was to find gasoline's ability to dissolve oxygen. From the research it was reckoned that the Dissolved Oxygen and free water present in the tanked Gasoline, could result in electrochemical corrosion over a period of time.
\end{abstract}

Keywords: tank corrosion, gasoline, dissolved oxygen, electrochemical, oil-water interface.

https://doi.org/10.47412/FMSX8723

\section{Introduction}

Gasoline or petrol is a derived product of crude oil or petroleum. It is derived during a fractional distillation process and is a translucent liquid form. Gasoline is a complex mixture of non-polar compounds such as long chained hydrocarbons, having boiling point ranges from 38 to $205^{\circ} \mathrm{C}$, this is determined by the American Society for Testing and Materials (ASTM) method [1]. Gasoline is a clear colourless, amber volatile liquid that is highly flammable in liquid and vapour form. It is primarily used as a fuel in internal combustion engines. Gasoline itself is not soluble in water, it is hydrophobic meaning it does not interact well with water. Gasoline varies by grade, there are three main grades of Gasoline that companies usually produce, and they include: Regular, Midgrade and Premium. Companies usually have various names for the grades of Gasoline such as Unleaded, Super or Super Premium. Controlling of oxygen may be utilized to trend the oxygen level, or determine the oxygen reactant concentration to decipher the need for oxygen scavengers, antioxidants or other oxygen reactive inhibitor additives [2].

A Dissolved Oxygen Probe was used to measure the concentration of Dissolved Oxygen (DO) in milligrams per litre (mg/L) in Gasoline. There are two main types of Dissolved Oxygen Sensors, they include Optical Sensors and Electrochemical Sensors.

The YSI Model 5905/5010/200-BOD/Pro-BOD (Biochemical Oxygen Demand) Probe was used to measure the Dissolved Oxygen. It is a Polarographic Dissolved Oxygen sensor, which contains an oxygen 
permeable membrane that covers an electrolytic cell encompassing of an anode and a cathode. The membrane of the probe operates in such a way that it is a diffusion barrier and an isolation barrier prohibiting the fouling of the cathode surface by impurities in the environment. The anode is a silver electrode while the cathode is a gold electrode which completes the electrolytic cell and operates like a reference electrode. The probe has a feature of self-stirring along with easily replaceable membrane caps and when it is plugged on to an YSI meter, readings are displayed for the Dissolved Oxygen Content in $\mathrm{mg} / \mathrm{L}$.

\subsection{Sparging and Mass Transfer Coefficient}

The most frequently used technique to decipher the mass transfer coefficient, $k_{L a}$ in bubbling gas-liquid contactors is oxygen into water or aqueous solutions, or the desorption of such a gas from a solution into sparging inert gas such as air or nitrogen. By using a sensor for determining the oxygen content, one can find the time-dependent concentration of Dissolved Gas at an adequately quick feedback to variations in concentration [3].

Sparging is defined as the process of injecting a gas through a diffuser into a liquid phase. When nitrogen gas is sparged into Gasoline the overall oxygen content would be reduced, this is known as oxygen stripping. The equation used to determine the mass transfer coefficient is shown below [4]:

$$
\frac{d C}{d t}=k_{L a}\left(C_{i o}-C\right)
$$

By Separating Variables and Integrating with respect to time the following equation was attained for the Mass Transfer Coefficient.

$$
k_{L a}=\frac{1}{t} \ln \frac{\left(C_{i o}-C_{1}\right)}{\left(C_{i o}-C_{2}\right)}
$$

Where:

$\boldsymbol{C}_{\mathbf{1}}$ and $\boldsymbol{C}_{\mathbf{2}}$ are the oxygen concentrations at stage 1 and 2 respectively, $\mathrm{mg} / \mathrm{L}$

$\boldsymbol{d} \boldsymbol{C} / \boldsymbol{d} \boldsymbol{t}$ is the accumulation oxygen rate in the liquid phase

$\boldsymbol{C}_{\boldsymbol{i o}}$ is the saturation concentration of dissolved oxygen in liquid phase, $\mathrm{mg} / \mathrm{L}$

$\boldsymbol{k}_{\boldsymbol{L}} \boldsymbol{a}$ is the volumetric coefficient of oxygen transfer

$\boldsymbol{t}$ is the time, mins

Corrosion is defined as the deterioration of a substance or its properties due to interactions between the substance and its environment [5]. Corrosion causes the deterioration of a metal and occurs when most or all the atoms on a metal surface is oxidized. Most metals are easily oxidized, they tend to lose electrons to oxygen in the air or in water. When oxygen is reduced, it forms an oxide with the metal.

Whenever petroleum products are in contact with metal parts and alloys, Corrosion is likely to take place, whether during production, operation distribution or even storage. Water content in refinery fuels is normally very low, about 30-80 ppm but if this is increased (for example, due to the penetration of steam or absorption of moisture in cold condition, into storage tanks), it would have an adverse effect on corrosion processes. In Gasoline with a water content of $80 \mathrm{ppm}$ or less, the rate of corrosion on carbon steel is 0.001 $\mathrm{mm} /$ year; in those with a water content of $200 \mathrm{ppm}$, the corrosion rate is as high as $0.40 \mathrm{~mm} /$ year.

\section{Methodology}

YSI 5905/5010/200-BOD/Pro-BOD Dissolved Oxygen Probe Kit is required for this investigation. This contains the following: Dissolved Oxygen Probe, YSI Meter, Extra Membranes and Electrolyte Solution for the Probe. $500 \mathrm{ml}$ of Gasoline was poured into a Biological Oxygen Demand (BOD) bottle. 
The YSI 5905/200-BOD/Pro-BOD was plugged into the YSI meter and the stirrer power plug was plugged into a power adapter. The Dissolved Oxygen Probe was placed into a BOD bottle containing of at least $300 \mathrm{ml}$ of Deionized Water. When the YSI 5905/5010/200-BOD/Pro-BOD Probe was powered on it was allowed to warm up for 5 minutes before any readings were taken, this was done to permit the probe to use up all the oxygen retained in the cap. In calibrating the Gasoline, it was ensured that there were no water droplets on the membrane of the YSI 5905/5010/200-BOD/Pro-BOD Probe, since this could have caused a low calibration reading. The probe was shaken downward to remove any excess water that maybe present in the probe, if there were droplets of water then a paper towel or a lint free cloth was taken and the tip of the probe was gently wiped. After setting up the Dissolved Oxygen Probe and YSI meter, the YSI 5905/5010/200-BOD/Pro-BOD Probe was switched on and a time of one minute was allowed to pass until the readings on the YSI meter stabilized. Once the readings were stabilized the Dissolved Oxygen concentration of Gasoline in milligrams per litre $(\mathrm{mg} / \mathrm{L})$ was taken note of. When the probe was not in use, it was placed back into the Biological Oxygen Demand (BOD) bottle containing of at least $300 \mathrm{ml}$ of Deionized Water.

The Gasoline was purged for 30 minutes by sparging Nitrogen gas into the BOD bottle containing Gasoline. When the Dissolved Oxygen concentration reached close to zero, the sparging of Nitrogen Gas was switched off and the BOD bottle was immediately covered back. Steps were repeated and the speed of the stirrer was varied ati500, 600 and $700 \mathrm{rpm}$. Now consecutively deionised water and the mixture of gasoline \& deionised water were sparged with $\mathrm{N}_{2}$ to make oxygen free.

Readings of the Dissolved Oxygen Concentration from the YSI meter were recorded every half an hour to observe the behaviour of Dissolved Oxygen in Gasoline, Deionized Water and mixture at different stirred speed.

\section{Result and Discussion}

To carry out the objectives of the research project an experiment was first conducted over a period of five (5) days where, $500 \mathrm{ml}$ of Gasoline was poured into a BOD bottle and everyday a reading using the Probe was taken. The probe was used in such a way that it was connected to a YSI meter and plugged on to a power source. When the switch was turned on in the Dissolved Oxygen Probe a reading was displayed on the YSI meter within one minute. This reading obtained was the concentration of Dissolved Oxygen (DO) in the Gasoline. After attaining readings, it was concluded that the YSI 5905/5010/200-BOD/Pro-BOD Dissolved Oxygen Probe did work with the non-polar solvent Gasoline and it was decided that a series of experiments would be done to fulfil the objectives of the research project.

From Fig. 1 it can be seen more clearly the behaviour of the DO concentration with an increase in time at each stirring speed. Initially all readings started off at approximately $6.4 \mathrm{mg} / \mathrm{L}$, this was the DO concentration of the Gasoline before the purging of nitrogen gas. From Fig. 1, a sudden drop is observed; this drop is due to the purging of nitrogen gas into the Gasoline. The Gasoline was then left untouched and the BOD bottle was covered and sealed for $30 \mathrm{mins}$, after that cover from the BOD bottle was removed and immediately the DO probe was placed into the mouth of the BOD bottle and switched on simultaneously along with the stirrer. These steps were very important and it had to be ensured that it was done as fast as possible to prevent any air from entering the BOD bottle containing the Gasoline since this could have been one of the sources of error in the experiment.

From Fig. 1 it can also be seen that when the stirring speed was at $400 \mathrm{rpm}$ it took the longest time for the Dissolved Oxygen concentration to become constant or to reach its equilibrium point. This could have occurred because the Gasoline was left for 30 minutes before another reading was taken, when the reading was to be taken, the stirrer had to be turned on, the speed at $400 \mathrm{rpm}$ could have been too little to create an even distribution in the Gasoline and hence it took a longer time for it to reach an equilibrium point. When 
the DO concentration became constant, the maximum amount of Dissolved Oxygen is present in the Gasoline and the experiment was stopped. It was noted that the experiment could have been carried on for a much longer period, as oxygen would always be diffusing into the Gasoline and its DO concentration would continuously increase as long as the Gasoline was exposed to atmospheric conditions such as the temperature of the surroundings.

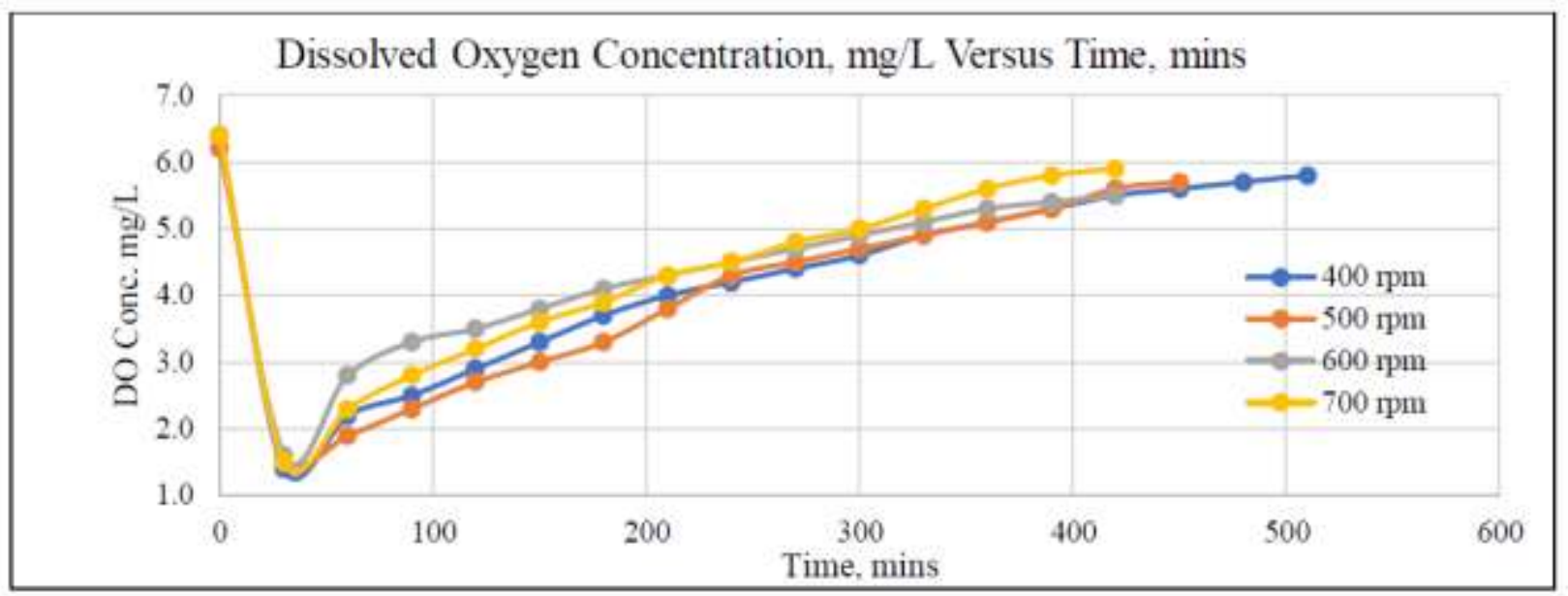

Figure 1: Graph showing a plot of Dissolved Oxygen Concentration (mg/L) Versus Time (mins) for Gasoline at stirring speeds of 400, 500, 600 and $700 \mathrm{rpm}$.

From Fig. 2 there was a sudden drop in the DO concentration of the deionized water, this was obtained because of purging the deionized water with nitrogen gas. After purging the deionized water was left in the BOD bottle covered and sealed until 30 minutes passed. Then the stirrer was turned on, the BOD bottle cover was removed and immediately the DO probe was placed into the bottle and switched on, the DO concentration was recorded. There was a very slow increase of the DO concentration for stirring speeds of 400 and $500 \mathrm{rpm}$.

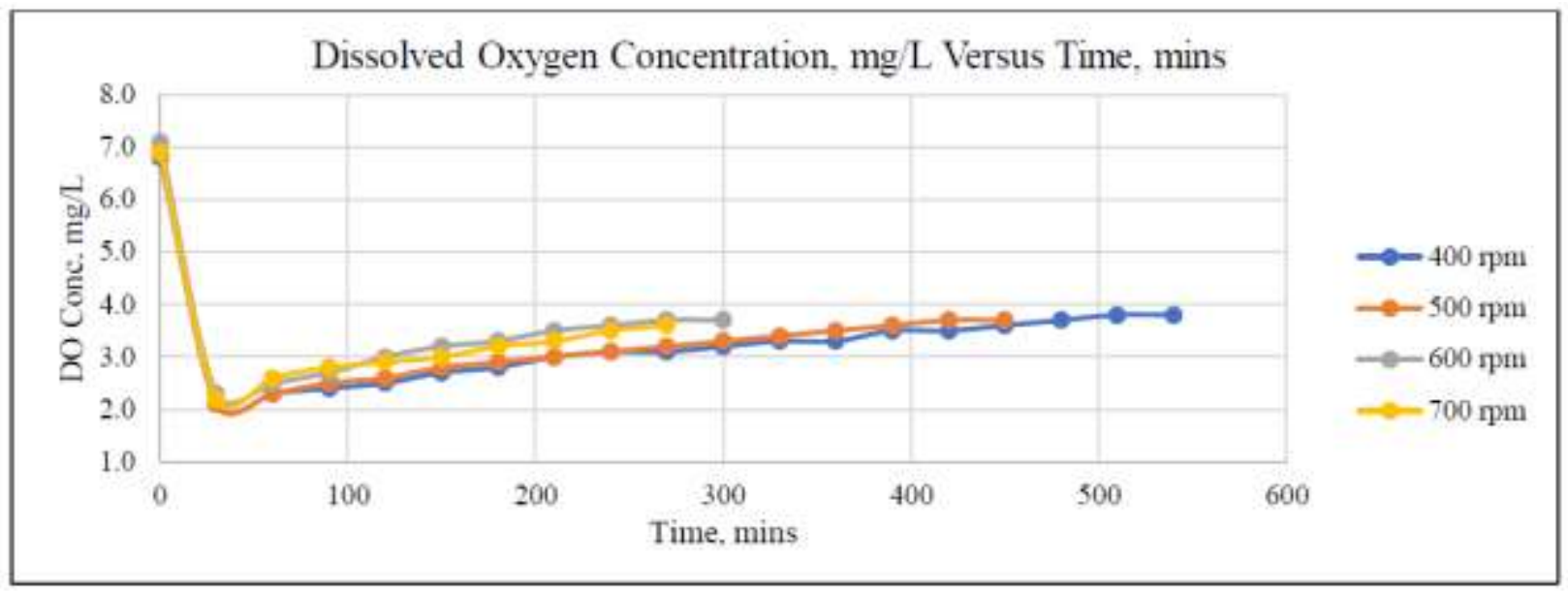

Figure 2: Graph showing a plot of Dissolved Oxygen Concentration (mg/l) Versus Time (mins) for Water at stirring speeds of 400, 500, 600 and $700 \mathrm{rpm}$. 
After performing experiments with the sparging of Gasoline and then the sparging of Deionized Water was done. After these two, a series of experiments were performed with a mixture of Gasoline and Deionized Water. Firstly, nitrogen was sparged into a 2:1 ratio of Gasoline and Deionized Water. From Fig. 3 below it can be seen that from the time, 0 mins, the mixture of Gasoline and Deionized Water had a DO concentration of $6.1 \mathrm{mg} / \mathrm{L}$, after introducing nitrogen gas it dropped to $1.60 \mathrm{mg} / \mathrm{L}$. The mixture was left for 30 minutes and then another reading of the DO concentration was taken, it was found to be increasing up until a time of 270 minutes where the DO concentration drastically dropped from $9.20 \mathrm{mg} / \mathrm{L} \mathrm{to} 6.60 \mathrm{mg} / \mathrm{L}$, the readings continued to decrease after that point. The reason for this could have been the fact that two completely different liquids were used and when they were put together, they did not mix. Gasoline and Water would never mix therefore this could have been a cause for the readings to fluctuate when the DO concentration reading was taken with the probe.

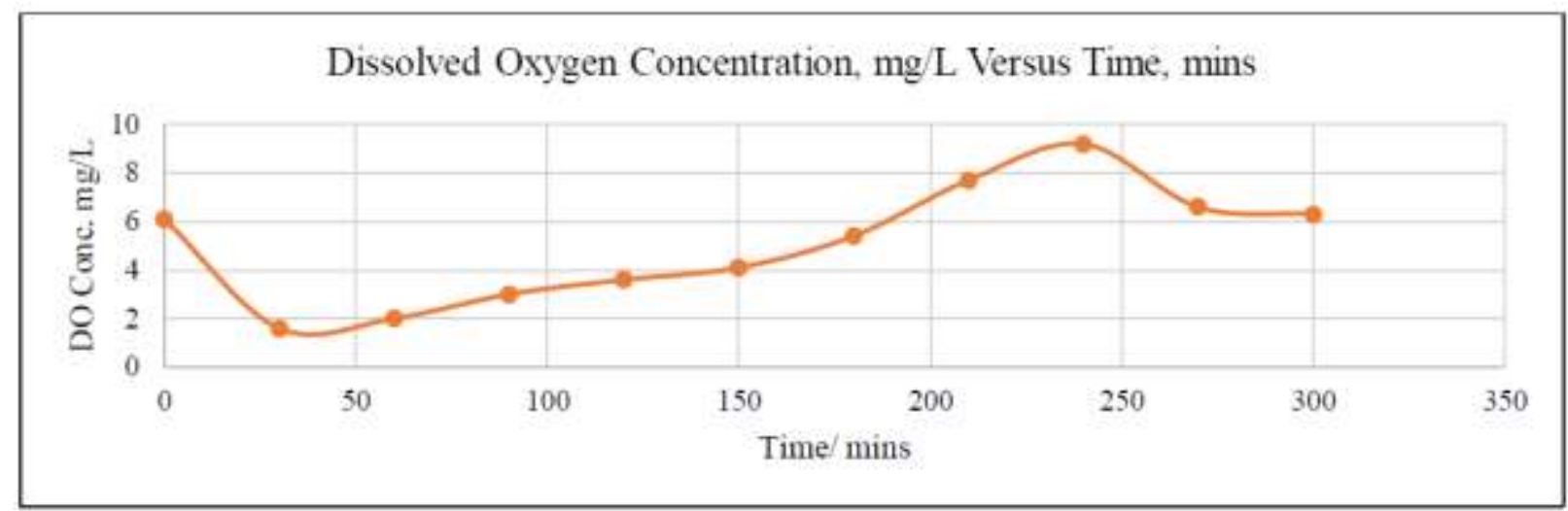

Figure 3: Graph showing a plot of the Dissolved Oxygen Concentration (mg/L) Versus Time (mins) for a 2:1 ratio of Gasoline and Deionized Water.

A 1:1 ratio of a mixture of Gasoline and Deionized Water was also looked at and the same behavior was observed (Fig. 4) where, the DO concentration reached a maximum of $9.1 \mathrm{mg} / \mathrm{L}$ at $180 \mathrm{mins}$ and then dropped at $6.30 \mathrm{mg} / \mathrm{L}$ at the time of 300 mins.

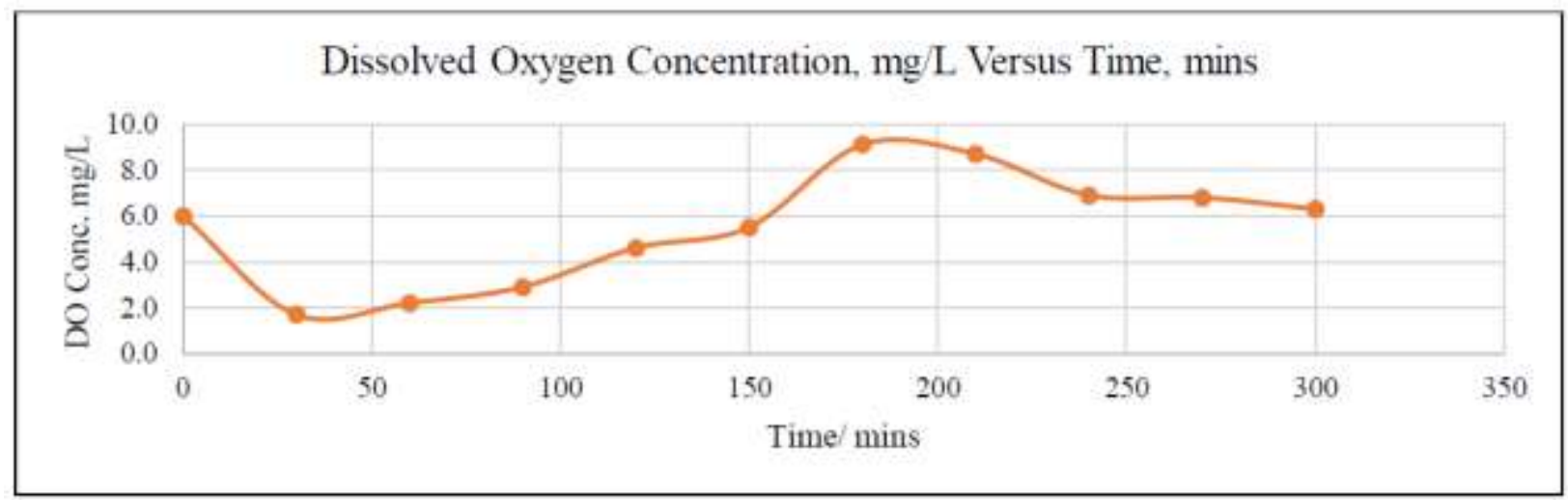

Figure 4: Graph showing a plot of the Dissolved Oxygen Concentration (mg/L) Versus Time (mins) for a 1:1 ratio of Gasoline and Deionized Water.

Once there is free water present in the Gasoline there would be Dissolved Oxygen present also because of the water [6]. The free water present with the Dissolved Oxygen is the main contributor of corrosion. 
Significant levels of water can be present in Gasoline storage tanks either when it is left for a prolonged period of time in storage or during transportation of the Gasoline.

To determine the mass transfer coefficient, a graph of $\ln \left[\left(\boldsymbol{C}_{\boldsymbol{i o}}-\boldsymbol{C}_{1}\right) /\left(\boldsymbol{C}_{\boldsymbol{i o}}-\boldsymbol{C}_{2}\right)\right]$ Versus $(\boldsymbol{t})$ was plotted for each experimental run, that is for each stirring speed of Gasoline and Deionized Water. The gradient from the straight line was taken and this was the mass transfer coefficient of each stirring speed run. Graphs were plotted to demonstrate the patterns of these results obtained, Fig. 5 and Fig. 6 show a general increase in MTC as the stirring speed increases.

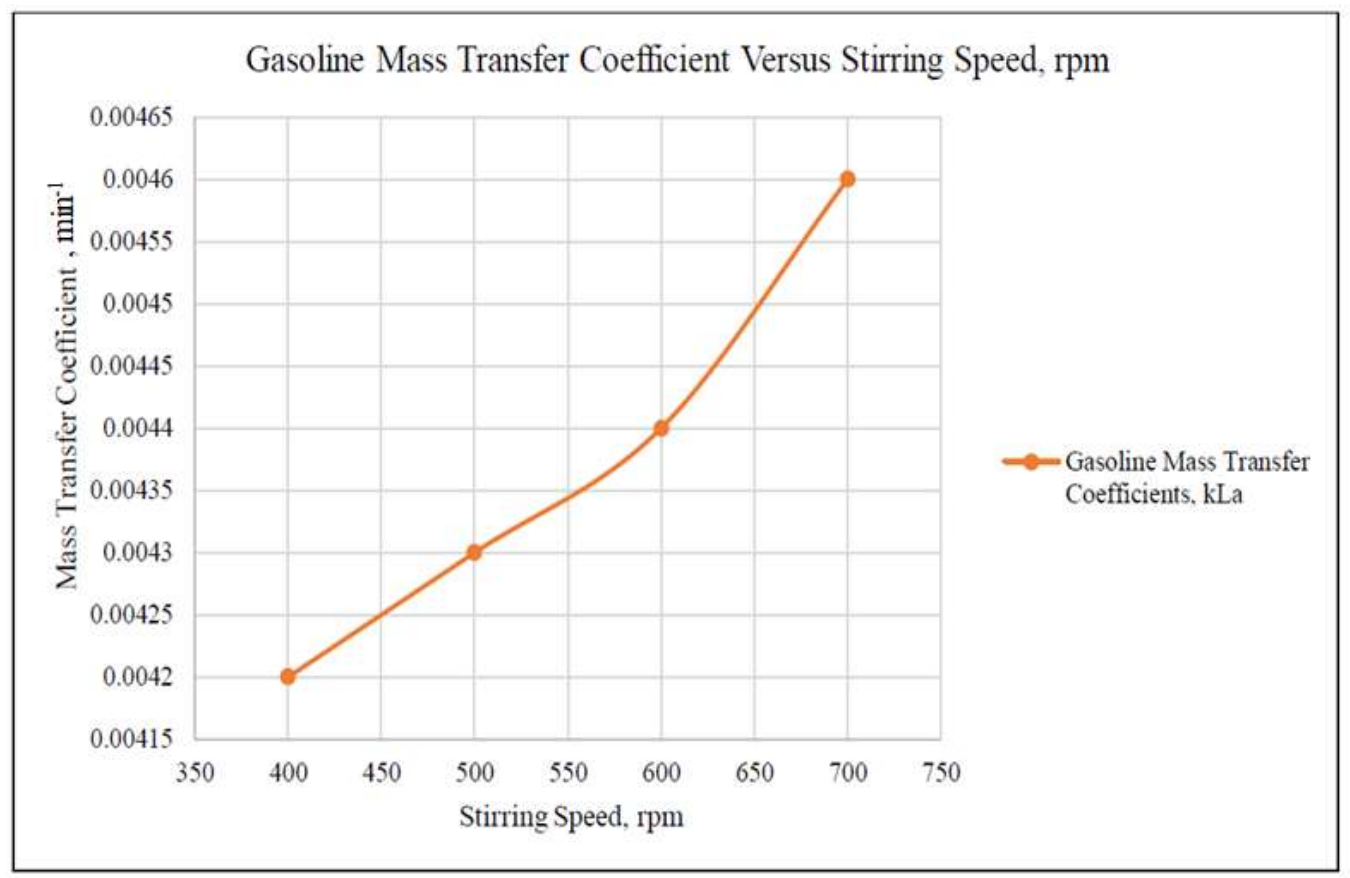

Figure 5: Graph showing a plot of Mass Transfer Coefficient Versus the Stirring Speed, rpm.

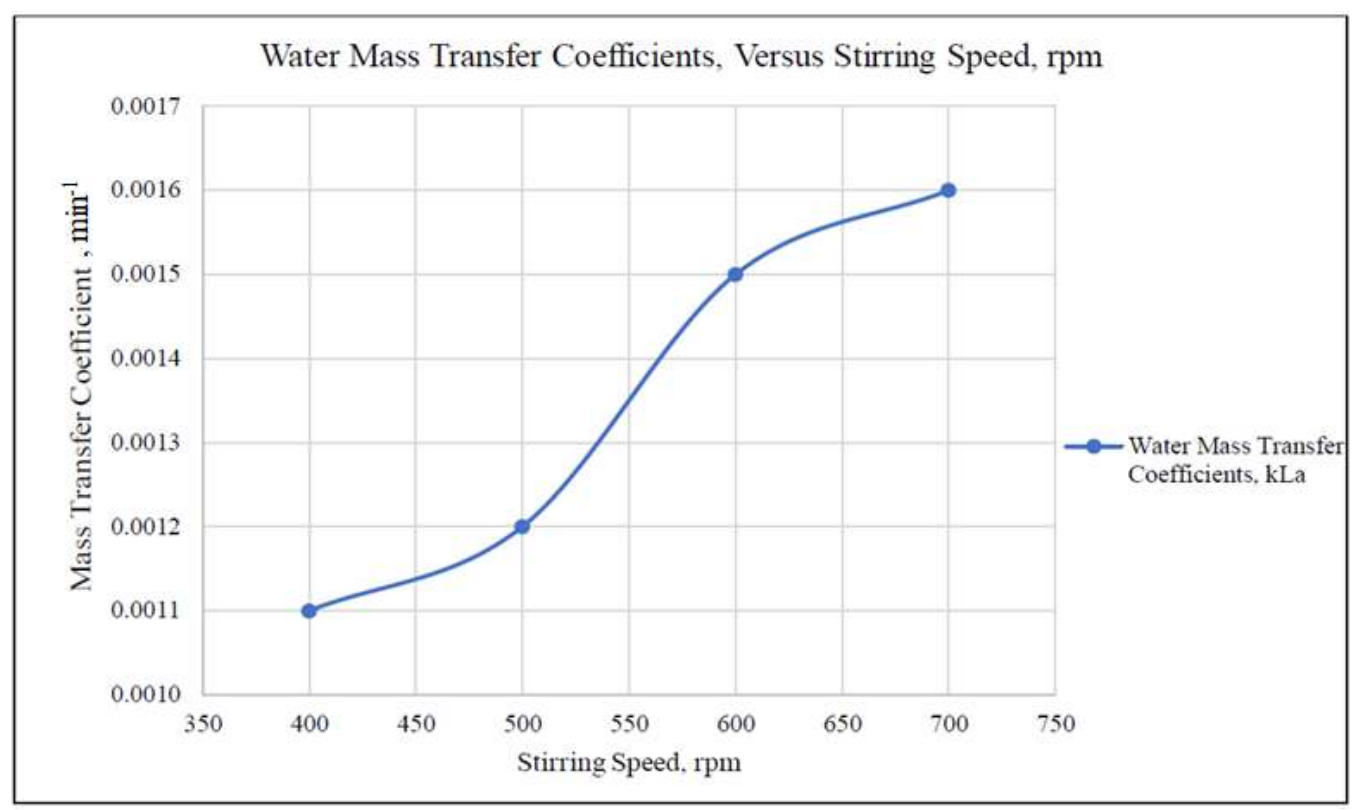


Figure 6: Graph showing a plot of Mass Transfer Coefficient Versus the Stirring Speed, rpm.

\section{Conclusion}

Based on the results gathered using the YSI 5905/5010/200-BOD/Pro-BOD Dissolved Oxygen Probe, presence of Dissolved Oxygen is evident in Gasoline. With increasing stirring speed, the Dissolved Oxygen concentration in Gasoline as well as in Deionized Water increases. It generally takes a shorter time for the Dissolved Oxygen Concentration to reach equilibrium in Gasoline at any stirring speed. In determining the mass transfer coefficients of Gasoline and Deionized Water it was found that Gasoline displayed a higher mass transfer coefficient value than Deionized Water. Therefore, As the stirring speed increases, the mass transfer coefficient increases too. So, the Dissolved Oxygen in stored Gasoline may interact with free water in gasoline tank to result in the electrochemical corrosion over a prolonged period of time.

\section{References}

[1] J. H. Gary, G. E. Handwerk, M. J. Kaiser. 2007. Petroleum Refining: Technology and Economics. 5th Edition, CRC Press, Boca Raton, 488

[2] H. Mo, R. D. Metzler, 2015, Methods of Measuring Dissolved Oxygen in a Hydrocarbon Stream, US20150072436A1.

[3] S. Katoh, F. Yoshida. 2009. Biochemical Engineering: A Textbook for Engineers, Chemists and Biologists. Wiley, 328

[4] D. Moutafchieva, D. Popova, M. Dimitrova, S. Tchaoushev. Experimental Determination of the Volumetric Mass Transfer Coefficient, Journal of Chemical Technology and Metallurgy, 48 No. 4 (2013) 351-356.

[5] R. Singh. Corrosion control and monitoring. 2014. Corrosion Control for Offshore Structures: Cathodic Protection and High Efficiency Coating, 244

[6] A. Groysman, 2017. Corrosion Problems and Solutions in Oil Refining and Petrochemical Industry. Springer. 182 